\title{
DEGRADAÇÃO DE GNAISSE E GRANITO EM FACHADAS DE EDIFÍCIOS HISTÓRICOS NO CENTRO DO RIO DE JANEIRO
}

\section{José Antônio Baptista Neto \\ jabneto@id.uff.br \\ Universidade Federal Fluminense - \\ UFF, Niterói, Rio de Janeiro, Brazil.}

\section{Christine Gaylarde}

cgaylarde@gmail.com University of Oklahoma, Oklahoma, United States of America

\section{Iwona Beech}

iwonabeech@hotmail.com Montana State University, Bozeman, United States of America

\section{Bernard J. Smith (in}

\section{memorian)}

Queen's University Belfast, Belfast, United Kingdom

\section{John J. McAlister}

johnmcalister6@gmail.com

Queen's University Belfast, Belfast, United Kingdom

\section{RESUMO}

A maioria do patrimônio cultural construído na cidade do Rio de Janeiro, Brasil, é feito de gnaisse ou granito, e a exposição das fachadas ao ambiente poluído leva a uma forte degradação. Para entender estes processos meteorológicos, foram estudados cinco edifícios históricos na cidade. Estes exibiram manchas de ferro, desintegração granular, boIhas, fraturas incipientes e escamação de contornos e desenvolvimento de crosta negra. As amostras coletadas nestes edifícios foram examinadas na tentativa de compreender os mecanismos da meteorologia de superfície. Amostras de rochas foram coletadas em áreas que apresentavam sérios sintomas de decomposição de rochas. $O$ conteúdo de ânions e cátions dos materiais de construção foi avaliado por espectrometria AA e análise cromatográfica de íons. As amostras também foram estudadas por microscopia de emissão de campo (SEM), análise petrográfica e pelo seu conteúdo biológico por SEM e análise de DNA usando Illumina Mi-Seq Next Generation Sequencing. Todas as análises químicas mostraram altas concentrações de sais solúveis, tais como halita e gesso, que desempenham um papel muito importante na resistência à intempérie da pedra. A FE-SEM com análise dispersiva de energia permitiu a detecção dentro da rocha de fungos filamentosos esparsos, grupos de células bacterianas, diatomáceas raras e bactérias filamentosas fotossintéticas especialmente interessantes incrustadas com gesso reprecipitado, mostrando a participação de microrganismos na degradação da pedra.

Palavras-chave: intemperismo, crosta negra, poluição urbana, decomposição rochosa. 


\section{INTRODUÇÃO}

Uma parte substancial do património tangível mundial é construída a partir de rochas (Scheerer et al., 2009). As rochas são materiais cujas características são estáveis em condições de alta pressão ou temperatura sob as quais foram formadas dentro da crosta terrestre. Quando ficam expostas à superfície, porém, encontram diferentes regimes de temperatura e pressão, e são expostas recentemente a uma série de substâncias como a água, gases atmosféricos e organismos vivos. Nessas condições, elas se tornam instáveis e sofrem mudanças consequentes nas propriedades materiais e na composição mineralógica (Mottershead et al., 2003). Muitos edifícios de interesse cultural estão localizados em ambientes urbanos, onde a poluição causada pelo tráfego rodoviário e pela indústria tem consequências nocivas para os materiais de construção e decoração de exteriores e interiores (Fassina, 1991; Sabbioni e Zappia, 1992; Sabbioni et al., 1996; Goudie e Viles, 1997; Van Grieken et al., 2000; Esbert et al., 2001; Moropoulou et al., 2001; Smith et al., 2002; Jordan et al., 2009). No exterior dos edifícios, o impacto dos gases ambientais, partículas liberadas pela combustão de combustíveis fósseis e de organismos biológicos aéreos leva à formação de crostas negras e outros efeitos estéticos indesejáveis, podendo também comprometer a integridade dos materiais (Esbert et al., 2001; Moropoulou et al., 2001; Bonazza et al., 2005; Sanjurjo Sánchez et al., 2009; Xu et al., 2010). A formação de crostas de intemperismo em pedras naturais em áreas urbanas é considerada fator importante na decomposição das pedras (Amoroso \& Fassina, 1983; Török, 2003, Baptista Neto et al., 2006). Durante a decomposição de um edifício de pedra, além das características intrínsecas do próprio material de construção (composição química e mineralógica, propriedades petrofísicas etc.), também estão envolvidas as características ambientais do local do edifício (Iñigo \& Vicente-Tavera, 2001).

O objetivo deste estudo é examinar os principais agentes que afetam a degradação de alguns edifícios históricos importantes no centro do Rio de Janeiro (Figura 1).

\section{CONDIÇÕES DO MEIO AMBIENTE}

A área metropolitana do Rio de Janeiro $\left(6.500 \mathrm{~km}^{2}\right)$ é a segunda mais populosa e uma das áreas mais prósperas do Brasil. De acordo com o Instituto Brasileiro de Geografia e Estatística (IBGE), em 2014 a área metropolitana abrigou 12.229.867 habitantes. Esta área apresenta um clima subtropical úmido, uma temperatura média anual de $22 \% \mathrm{C}$, com temperaturas de verão variando de $30-32 \circ \mathrm{C}$ e precipitação média de 1200-1800 mm. A variação temporal da precipitação resulta em períodos secos (de junho a agosto) e úmidos (de novembro a março), com diferenças marcantes nas entradas médias de precipitação. Embora a precipitação se concentre entre novembro e março, pode haver chuva e umidade relativa durante qualquer mês, especialmente em locais litorais. Portanto, a pluviosidade permanece elevada durante todo o ano, juntamente com as elevadas concentrações de aerossóis marinhos. Ocorreu um declínio significativo na qualidade do ar nas últimas décadas, causado pelo aumento das emissões de veículos. Agora é comum em condições de ar parado que a maior parte da área seja coberta por um nevoeiro fotoquímico (Smith et al., 2004). Este nevoeiro contém altas concentrações de partículas carbonáceas e ricas em sulfato que têm origem em emissões industriais de locais de construção, perturbações do solo e atividades de alvenaria (Daisey et al., 1987; Azevedo et al., 1999). Os aerossóis marinhos também podem ser adicionados a esta lista, uma vez que foram estimadas taxas de deposição de sódio e cloro de 2,2 e 4,2 t/km2/por ano, respectivamente (Moreira-Nordemann et al., 1988). A matéria orgânica extraível em aerossóis urbanos tem sido utilizada como marcador de combustíveis fósseis entre os hidrocarbonetos alifáticos monitorados em locais de baixo nível no Rio de Janeiro (Azevedo et al., 1999). Em outros lugares do estado do Rio de Janeiro, em ambientes industriais e urbanizados, Quiterio et al. (2004) identificaram, na ausência de controles rigorosos de emissões, concentrações de metais pesados e vestígios de partículas em suspensão no ar que atingem níveis significativamente superiores aos geralmente registrados para áreas semelhantes em todo o mundo. A presença destes metais em qualquer partícula depositada poderia catalisar a formação de gesso em superfícies de pedra (Camuffo et al., 1983). Além disso, os microrganismos depositados nas superfícies dos edifícios podem levar à neoformação de gesso, calcita ou outros depósitos (Gadd, 2017).

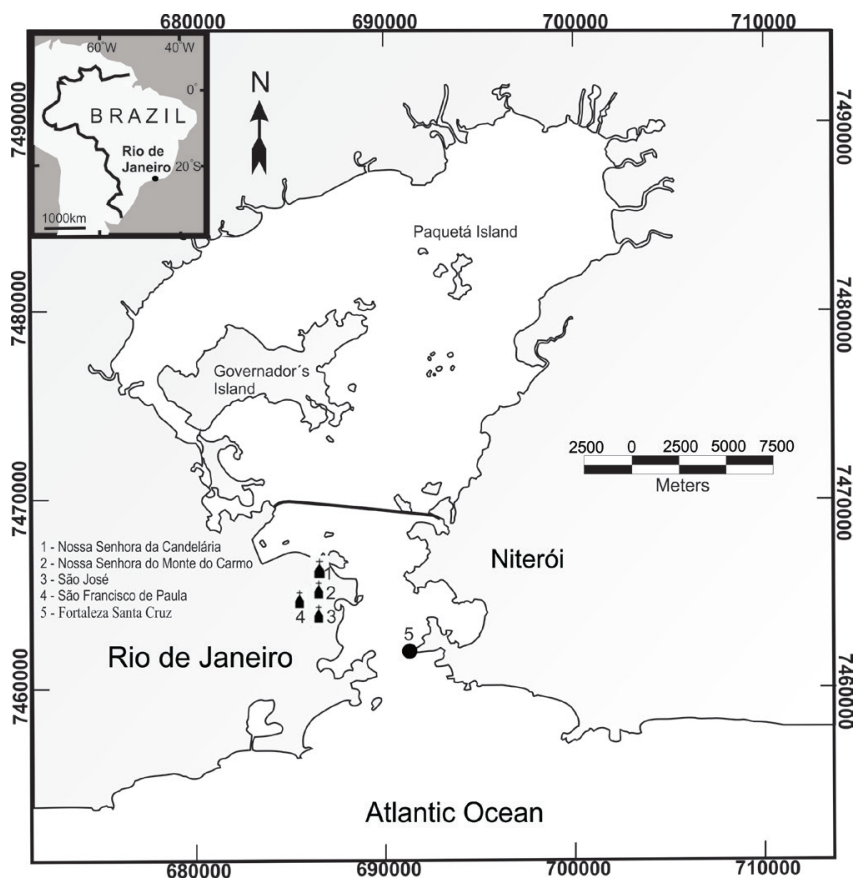

Figura 1. Mapa de localização dos locais estudados. 
De acordo com Smith \& Magee (1990), os altos níveis de emissões de veículos se refletem na aparência física e na sujeira de muitos edifícios dentro do centro da cidade, onde altas densidades de tráfego privado e comercial são frequentemente canalizadas ao longo das ruas ladeadas por edifícios altos. A poluição tende a se concentrar e persistir dentro desses corredores e seu efeito em longo prazo mais óbvio é a mancha negra de muitos edifícios perto do nível da rua.

\section{MATERIAIS E MÉTODOS}

\subsection{Amostragem e métodos analíticos}

A fim de identificar os principais agentes que afetam a rápida retirada de blocos na superfície de gnaisse em fachadas de edifícios históricos no centro do Rio de Janeiro, foram retiradas amostras das fachadas frontais de quatro igrejas localizadas no centro da cidade do Rio de Janeiro e da Fortaleza de Santa Cruz, em Niterói, Brasil: Nossa Senhora do Monte do Carmo (CA), situada na Praça XV de Novembro; São Francisco de Paula (SF), no Largo de São Francisco de Paula; São José (SJ), na Avenida Presidente Antônio Carlos; e Nossa Senhora da Candelária (C), localizada na Praça Pio X. A Fortaleza de Santa Cruz está localizada na entrada da Baía de Guanabara. Foram coletadas amostras de rochas em áreas que apresentavam crostas negras bem desenvolvidas, além de sérios sintomas de decomposição de pedras. No laboratório, as amostras foram analisadas por diversas técnicas a fim de identificar os principais agentes que poderiam influenciar os processos meteorológicos (McAlister, 1996). Em razão da sensibilidade da amostragem de edifícios históricos, só foi possível obter pequenas lascas (geralmente $<2 \times 2 \mathrm{~cm}$ ) a partir de crostas superficiais. Estas pequenas lascas de pedra de intemperismo e crosta negra foram montadas separadamente em tocos de alumínio e revestidas com ouro, e sua superfície foi analisada usando um microscópio eletrônico de varredura (SEM) (Joel Winsen JSM 6400). Outras amostras foram revestidas com ouro-paládio ou irídio, examinadas com uma emissão de campo (FE)-SEM e caracterizadas por espectroscopia de raios $X$ dispersiva de energia (EDS). Sais solúveis em água foram extraídos das frações $<63 \mu \mathrm{m}$, agitando $2 \mathrm{mg}$ de amostra em $10 \mathrm{ml}$ de água deionizada durante duas horas e permitindo que ficassem em repouso em temperatura ambiente antes da centrifugação e filtração através de filtros de membrana de $0,2 \mu \mathrm{m}$ para análise. Os cations $\mathrm{Na}, \mathrm{K}, \mathrm{Mg}, \mathrm{Ca}, \mathrm{Cr}, \mathrm{Mn}, \mathrm{Fe}, \mathrm{Ni}$, $\mathrm{Cu}, \mathrm{Pb}$ e $\mathrm{Zn}$ foram determinados usando um espectrômetro de absorção atômica Perkin Elmer Modelo 3100. Uma chama de ar/acetileno foi empregada para atomizar as soluções de amostra. Íons solúveis em água também foram extraídos de $0,5 \mathrm{mg}$ da amostra em $2,5 \mathrm{~cm}^{3}$ de água deionizada filtrada por membrana e após filtração por membrana $(0,2 \mu \mathrm{m})$, sendo submetidos à análise cromatográfica de íons. Os ânions solú- veis em água, $\mathrm{F}, \mathrm{Cl}, \mathrm{NO}_{3}, \mathrm{PO}_{4}$ e $\mathrm{SO}_{4}$, foram analisados usando um cromatógrafo de íons modelo Dionex DX 500. Uma coluna de guarda lon-Pac AG4A-SC ( $4 \mathrm{~mm}$ ) e uma coluna de troca de ânions AS4A-Sc (4m) foram utilizadas e o laço de injeção foi de $25 \mu \mathrm{L}$ de volume. Utilizou-se como eluente uma solução mista de $\mathrm{Na}_{2} \mathrm{CO}_{3}$ a $1,8 \mathrm{mM} / \mathrm{NaHCO}_{3}$ a $1,7 \mathrm{mM}$ a uma taxa de fluxo de $2 \mathrm{ml}$ por minuto, e o limite do detector de condutividade para todos os ânions foi de 1 ppm (Baptista Neto et al., 2006).

\subsection{Análise da população microbiana}

As populações microbianas nas amostras foram determinadas por Sequenciamento de Nova Geração (NGS). O DNA foi extraído das amostras e submetido a 16S rDNA (bactérias) e amplificação do gene ITS (fungos), seguido por NGS, como descrito em Gaylarde et al. (2017a; 2017b) e Ogawa et al. (2017a).

\section{RESULTADOS E DISCUSSÃO}

O Rio de Janeiro contém alguns dos mais importantes edifícios arquitetônicos coloniais do Brasil. Rochas Augen gnaisse e graníticas foram usadas na construção da maioria dos edifícios históricos da cidade, incluindo museus e igrejas (Smith e Magee, 1990; Smith et al., 2004; 2007; Mansur et al., 2008; Ricardo et al., 2017). Estes minerais também foram utilizados na produção de esculturas, ornamentações, fachadas e caixilhos de portas e janelas, devido à sua resistência ao intemperismo. Hoje em dia, no entanto, estes edifícios estão sofrendo um rápido recuo em bloco, mostrando sintomas de grave deterioração das pedras, que tem aumentado nas últimas décadas. A maioria dos edifícios e monumentos no centro do Rio de Janeiro é tipicamente enegrecida; isto é considerado devido ao acúmulo de poluentes atmosféricos em suas superfícies.

O grau de desgaste das fachadas das igrejas foi observado no campo. Foram selecionadas as áreas mais afetadas por crostas negras e intemperismos; manchas de ferro, desintegração granular, bolhas, fraturas incipientes e escamação de contorno das fachadas de pedra foram observadas em todos os edifícios. A Figura 2 mostra as principais patologias observadas nos edifícios.

As análises realizadas pela SEM nas amostras coletadas das crostas negras extraídas das fachadas dos edifícios mostraram altas concentrações de vários sais, como gesso e halita (Figura 3). A coloração negra e muitas vezes irregular da superfície pode ser observada em muitos edifícios históricos de pedra e estátuas em todo o mundo, diminuindo o seu valor estético. Os processos por detrás da produção destes revestimentos pretos finos são, no entanto, muito mais sérios do que apenas os aspectos estéticos. Eles estão ligados 
à meteorologia através da crescente poluição do ar, atividade microbiana e condições climáticas (Saiz-Jimenez, 1991; Fitzner et al., 1995; Galletti et al., 1997). A fim de observar a possível ocorrência de sais nas rochas, foram produzidos cortes finos petrográficos (Figura 4) que mostraram a formação de gesso nas microfraturas das rochas, indicando a importância deste sal na rocha envelhecida. Segundo Sabbioni (1995), a formação da crosta de gesso é devida à deposição úmida e seca do enxofre atmosférico e a subsequente transformação do carbonato de cálcio em sulfato de cálcio desidratado. Entretanto, as crostas negras desenvolvem-se em áreas protegidas por chuva de edifícios de pedra, após a deposição ácida (deposição seca) de poluentes atmosféricos (Rodriguez-Navarro e Sebastian, 1996). Segundo Baptista Neto et al. (2006), a fonte óbvia de cálcio na área de estudo é a argamassa nas juntas entre os blocos graníticos, que também é utilizada para "proteger" as áreas já afetadas pelos intemperismos. O cálcio também pode ter origem nas cinzas volantes que foram encontradas em todas as amostras analisadas. As partículas de cinzas volantes são esféricas, têm superfícies porosas irregulares, contendo altas concentrações de carbono, silício, enxofre, alumínio e cálcio e são provenientes principalmente de emissões veiculares (Del Monte et al., 1981). Atualmente, a maioria dos estudos sobre formação de crosta negra tem sido focada principalmente em pedras carbonatadas sedimentares e mármores (Brimblecombe e Grossi, 2007). A formação de crostas negras sobre rochas siliciosas, como granito e gnaisse, não tem sido estudada tão extensivamente como nas rochas calcárias (Silva et al., 2009, Pozo-Antonio et al., 2016).

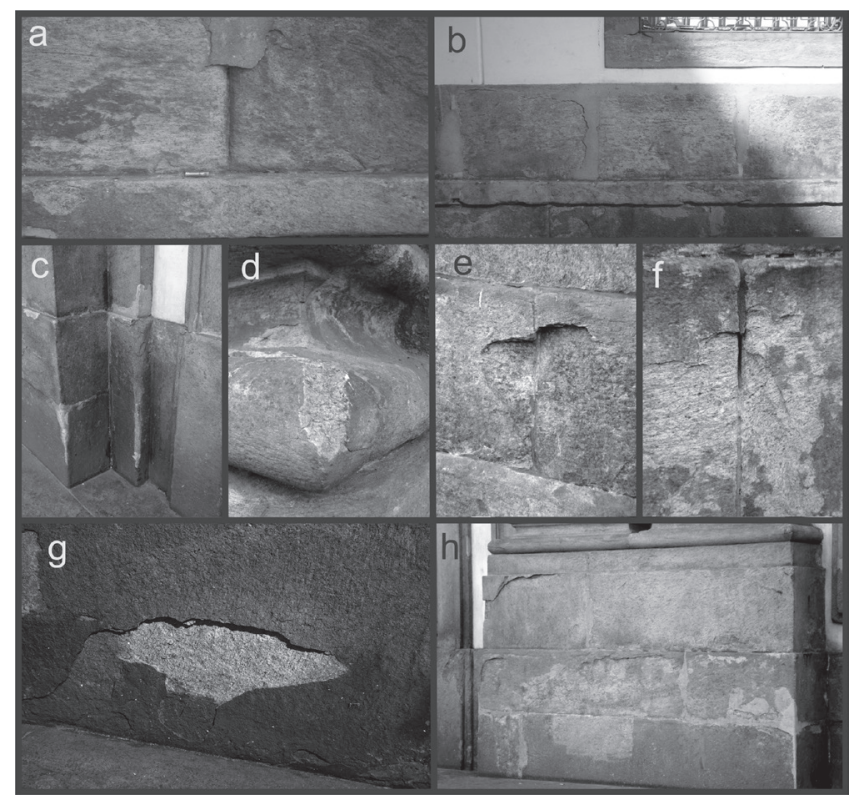

Figura 2. Fotografia mostrando as principais patologias observadas nos prédios da rua de frente para a fachada próximo ao nível da rua.

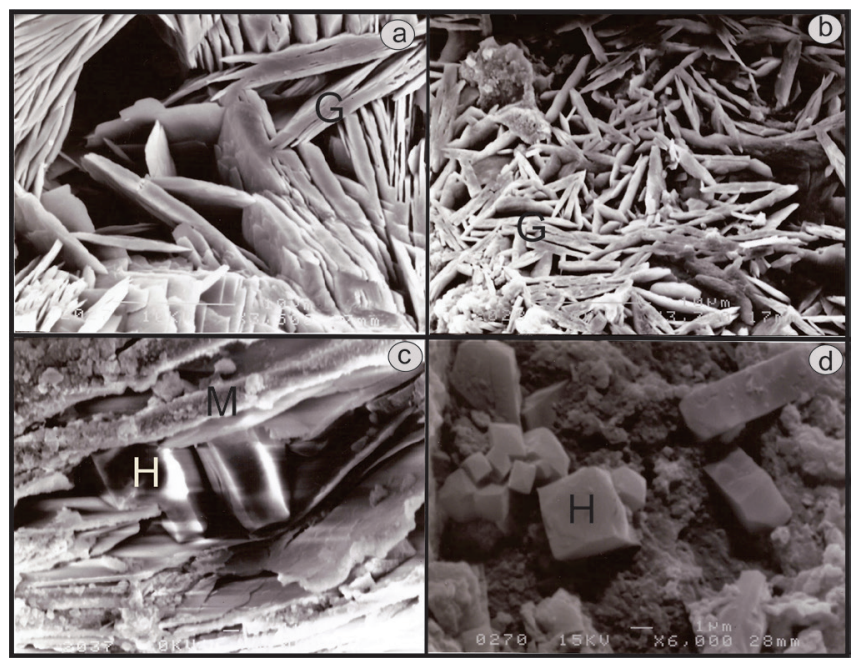

Figura 3. Micrografias SEM de crostas negras mostrando (A e B) cristais de gesso em forma de agulha acumulados na fachada de rocha e lacunas de cristais de halita entre planos de clivagem abertos em micas causando deformação e ruptura (C) e na superfície da rocha (D)

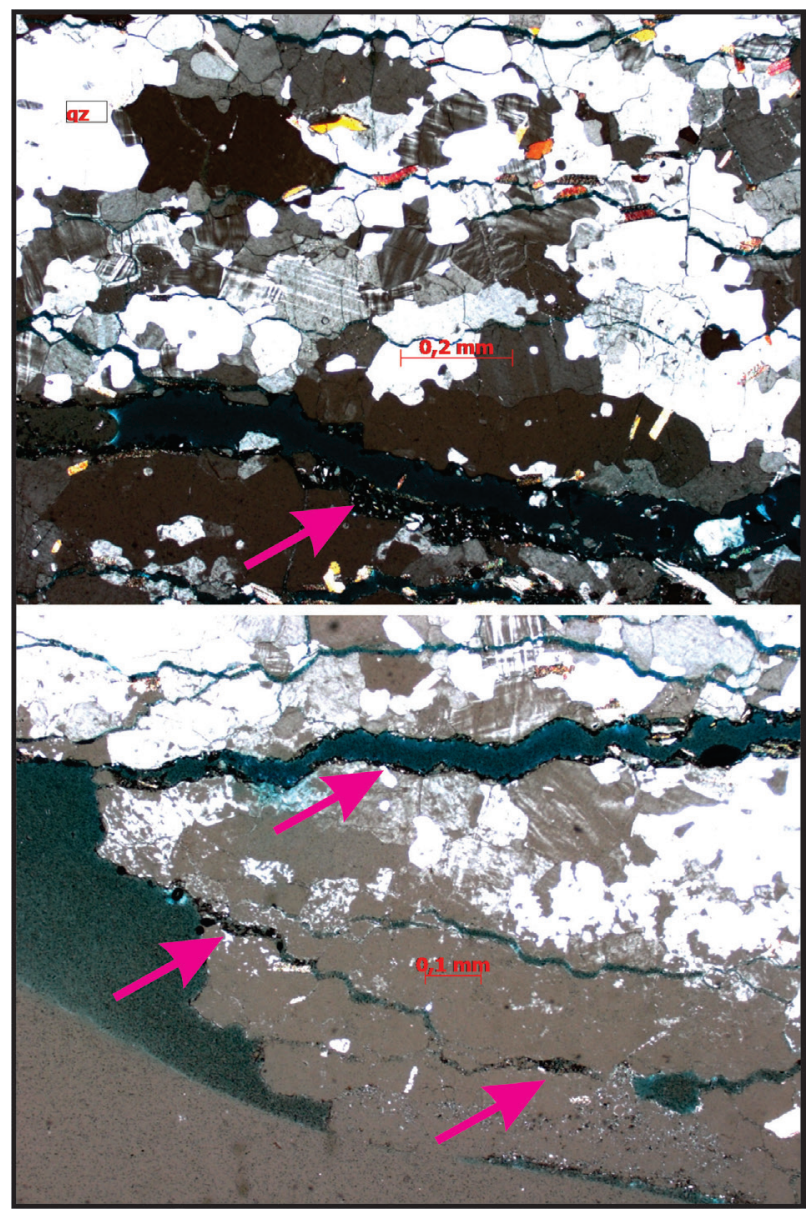

Figura 4. Seção fina petrográfica mostrou a formação de cristais de gesso nas microfraturas rochosas 
As análises geoquímicas realizadas por cromatografia iônica e AAS (Tabela 1), mostraram as altas concentrações de $\mathrm{Ca}, \mathrm{Na}, \mathrm{Cl}$ e $\mathrm{SO}_{4}$ em todas as amostras. A forte correlação entre elementos como $\mathrm{Ca}$ e $\mathrm{SO}_{4}$, mostrada na Figura 5, confirma a presença de gesso $\left(\mathrm{CaSO}_{4} \cdot 2 \mathrm{H}_{2} \mathrm{O}\right)$ em todas as fachadas dos edifícios; este sal já foi observado por outros estudos no Rio de Janeiro (Smith e Magee, 1990; Smith et al., 2004; Baptista Neto et al., 2007; Baptista Neto et al., 2011; Gaylarde et al., 2017). Também foi observada forte correlação entre os elementos $\mathrm{Na}$ e $\mathrm{Cl}$, que confirmaram a presença de hálito $(\mathrm{NaCl})$, relacionado à interação com aerossóis marinhos do mar na Baía de Guanabara. Esses dois sais desempenham um papel muito importante no intemperismo de cantaria e são agentes muito eficazes de intemperismo de sal quando encontram seu caminho para a cantaria (Smith et al., 2002). Vários autores mostraram que crostas negras também podem ter um importante componente biológico; numerosos organismos e microrganismos foram detectados em associação com as crostas (Ortega-Calvo et al., 1991; Crispim et al., 2006; Gaylarde et al., 2007). A colonização biológica e o crescimento de organismos, incluindo algas, fungos, líquenes, bactérias e cianobactérias, na superfície da pedra, reduzem o valor do monumento (Pozo-Antonio et al., 2016; ICOMOS, 2008). Esse crescimento biológico pode contribuir para a deterioração física e química (Piervittori et al., 2004; Gaylarde et al., 2012) e os microrganismos foram, de fato, identificados nas análises atuais.

Tabela 1. Ânions e cátions solúveis em água (ppm)

\begin{tabular}{|c|c|c|c|c|c|c|c|}
\hline Localização & $\mathrm{Cl}-$ & NO3- & SO2-4 & $\mathrm{Na}+$ & Mg2+ & $\mathbf{K}+$ & $\mathrm{Ca} 2+$ \\
\hline São José & 176.13 & 123.5 & 357.4 & 276 & 43.8 & 187 & 2837 \\
\hline São José & 65.51 & 73.9 & 150.4 & 65 & 21.4 & 190 & 2954 \\
\hline São José & 164.6 & 358.4 & 2156.8 & 286 & 16.7 & 288 & 2376 \\
\hline São José & 237.9 & 388.3 & 3040.87 & 286 & 48.5 & 240 & 2439 \\
\hline Nossa Sra do Carmo & 33.26 & 70.00 & 131.50 & 20 & 4 & 50 & 56 \\
\hline Nossa Sra do Carmo & 24.30 & 51.48 & 143.08 & 20 & 3.5 & 50 & 57.5 \\
\hline Nossa Sra do Carmo & 55.50 & 160.92 & 303.20 & 35 & 6 & 65 & 109.5 \\
\hline Nossa Sra do Carmo & 405.40 & 142.31 & 6730.78 & 150 & 20.5 & 180 & 2750 \\
\hline Nossa Sra do Carmo & 227.32 & 373.19 & 7079.05 & 150 & 43 & 130 & 2850 \\
\hline Nossa Sra do Carmo & 223.12 & 97.28 & 1239.47 & 185 & 24.5 & 160 & 450 \\
\hline São Francisco Xavier & 431.79 & 414.8 & 278.975 & 135 & 19 & 65 & 305 \\
\hline São Francisco Xavier & 24.48 & 49.785 & 176.3 & 25 & 7 & 75 & 75 \\
\hline São Francisco Xavier & 344.12 & 1147.34 & 2750.375 & 300 & 33.5 & 220 & 1160 \\
\hline São Francisco Xavier & 396.33 & 1160.065 & 7693.735 & 200 & 42.5 & 220 & 3600 \\
\hline São Francisco Xavier & 415.01 & 1162.24 & 6944.55 & 200 & 26 & 205 & 2850 \\
\hline São Francisco Xavier & 1646.09 & 3096.34 & 7835.09 & 750 & 125 & 460 & 3950 \\
\hline São Francisco Xavier & 89.28 & 194.93 & 3713.515 & 95 & 17 & 125 & 1345 \\
\hline Candelária & 170.32 & 75.19 & 99.12 & 45 & 15.5 & 15 & 85.5 \\
\hline Candelária & 389.79 & 376.26 & 347.82 & 215 & 33.5 & 55 & 305 \\
\hline Candelária & 172.32 & 113.11 & 224.64 & 55 & 5 & 95 & 255 \\
\hline Candelária & 597.63 & 984.25 & 3167.13 & 475 & 28.5 & 175 & 1754 \\
\hline Candelária & 414.98 & 843.76 & 3765.32 & 320 & 38.5 & 190 & 2973 \\
\hline Candelária & 353.75 & 917.38 & 4892.51 & 275 & 19 & 185 & 1894 \\
\hline Candelária & 487.84 & 1098.48 & 4623.95 & 490 & 35 & 375 & 2739 \\
\hline Candelária & 344.24 & 238.92 & 1083.91 & 215 & 25 & 95 & 1495 \\
\hline Candelária & 567.37 & 2156.13 & 6073.92 & 575 & 47.5 & 475 & 3775 \\
\hline Candelária & 647.32 & 3050.9 & 7683.19 & 850 & 55 & 550 & 3965 \\
\hline Forte de Santa Cruz & 11 & 0 & 29 & 27 & 6 & 18 & 19 \\
\hline Forte de Santa Cruz & 267 & 30 & 176 & 169 & 119 & 130 & 41 \\
\hline Forte de Santa Cruz & 2070 & 2923 & 7998 & 6559 & 0 & 53 & 761 \\
\hline Forte de Santa Cruz & 123 & 114 & 5753 & 178 & 9 & 1681 & 2740 \\
\hline Em branco & 87.6 & 0 & 0 & 0 & 0 & 0 & 0 \\
\hline
\end{tabular}



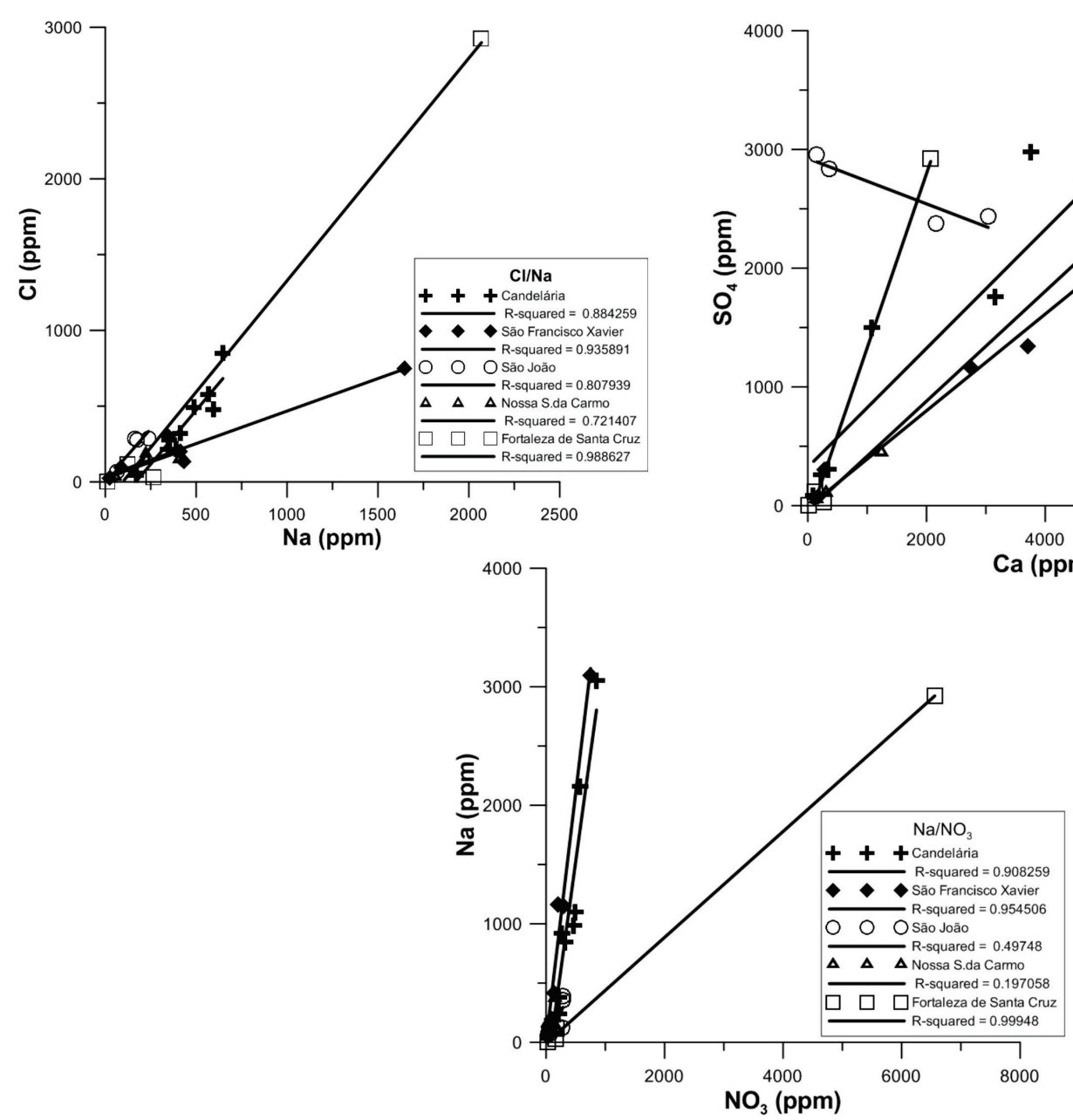

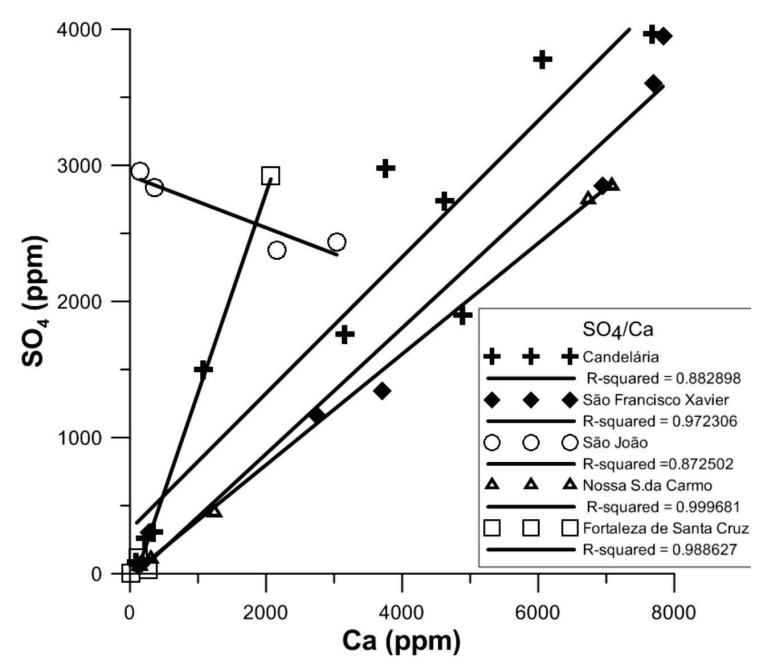

Figura 5. Correlação entre alguns elementos químicos.

O FE-SEM com a análise EDS permitiu a detecção na rocha de poucos fungos filamentosos, grupos de células bacterianas, diatomáceas raras e, bactérias fotossintéticas filamentosas especialmente interessantes (cianobactérias) incrustadas com gesso reprecipitado (Figura 6). Sabe-se que uma grande variedade de organismos biológicos solubiliza os minerais dentro de rochas (Meldrum e Cölfen, 2008). Sterflinger e Pinar (2013) sugeriram que os fungos poderiam ser os microrganismos mais importantes envolvidos na degradação da pedra, mas também é sabido que as cianobactérias podem penetrar e crescer nas rochas (Gaylarde et al., 2012), obviamente causando danos físicos apenas pela presença deles. No entanto, a capacidade das cianobactérias de solubilizar metabolicamente e depois permitir ou causar ativamente a redefinição e realocação de minerais está bem documentada em crostas de sal (Canfora et al., 2016), bem como em edifícios de arenito e itacuru, um tipo de rocha rica em ferro usada nas missões jesuítas na América do Sul (Tazaki et al., 2009; Barrionuevo et al., 2016). As bainhas gelatinosas de cianobactérias filamentosas e esféricas são consideradas locais de nucleação de depósitos de cálcio (Gerbersdorf e Wieprecht, 2015), e as cianobactérias detectadas nas amostras deste estudo também poderiam ser, pelo menos em parte, responsáveis pelos abundantes cristais de calcita encontrados, assim como os fungos filamentosos (Bindschedler et al., 2016).

A descoloração da superfície das fachadas foi certamente aumentada pela colonização microbiana e os microrganismos presentes foram identificados usando a técnica Next Generation DNA Sequencing. As populações detectadas eram típicas das que ocupavam ambientes estressantes, neste caso, superfícies de pedra de alta temperatura com poucos ou nenhum nutriente disponível e superfícies duras e lisas que favorecem o rápido escoamento da água (Gaylarde et al., 2017a; 2017b). Muitos dos grupos identificados continham microrganismos que produzem pigmentos coloridos (por exemplo, os géneros bacterianos e fúngicos $\mathrm{Ko}$ curia, Rubrobacter, Rhodotorula, e Sporobolomyces, assim como todos os fototróficos). Além disso, vários grupos eram termofílicos ou halofílicos, indicando as altas temperaturas e concentrações de sal da pedra. 


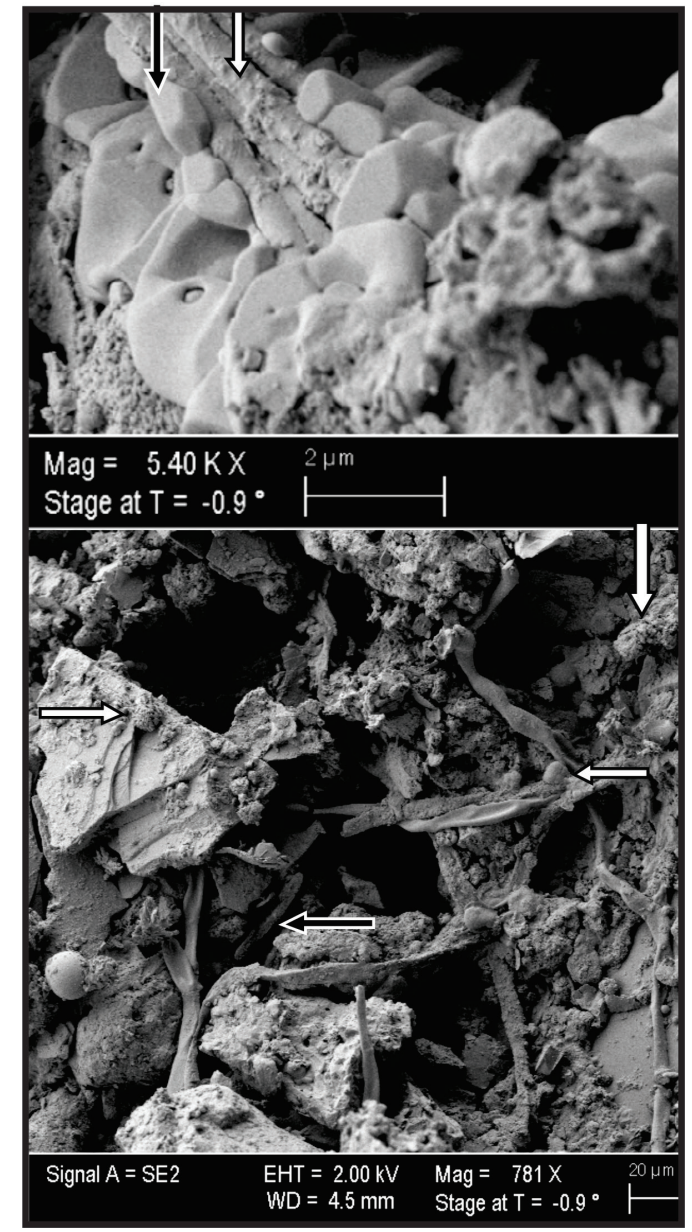

Figura 6. O FE-SEM com análise de EDS permitiu a detecção de bactérias fotossintéticas filamentosas (cianobactérias) incrustadas com gesso re-precipitado.

Líquenes foram vistos apenas ocasionalmente em algumas das superfícies (Figura 7); é provável que sua escassez se deva à atmosfera poluída do centro do Rio de Janeiro. Os líquenes são associações simbióticas de fungos com microrganismos fototróficos, algas ou cianobactérias, que por vezes são usados como indicadores da qualidade do ar, uma vez que são muito sensíveis à poluição atmosférica (Conti e Cecchetti, 2001). Os tipos de crostas são especialmente prejudiciais; produzem rizóides (pequenas raízes), que penetram no substrato de pedra, degradando-a (De Los Rios et al., 2009). O líquen folioso Parmelia saxatilis foi encontrado na superfície de parapeitos de pedra na Fortaleza de Santa Cruz, Niterói, Brasil (Ogawa et al., 2017b), uma área com pouca poluição urbana, próxima ao mar. Quando removido, com um peróxido de hidrogênio $\left(\mathrm{H}_{2} \mathrm{O}_{2}\right)$, os danos causados pela sua penetração na pedra, provavelmente acompanhados pela produção de ácido oxálico, puderam ser claramente observados (Figura 7).

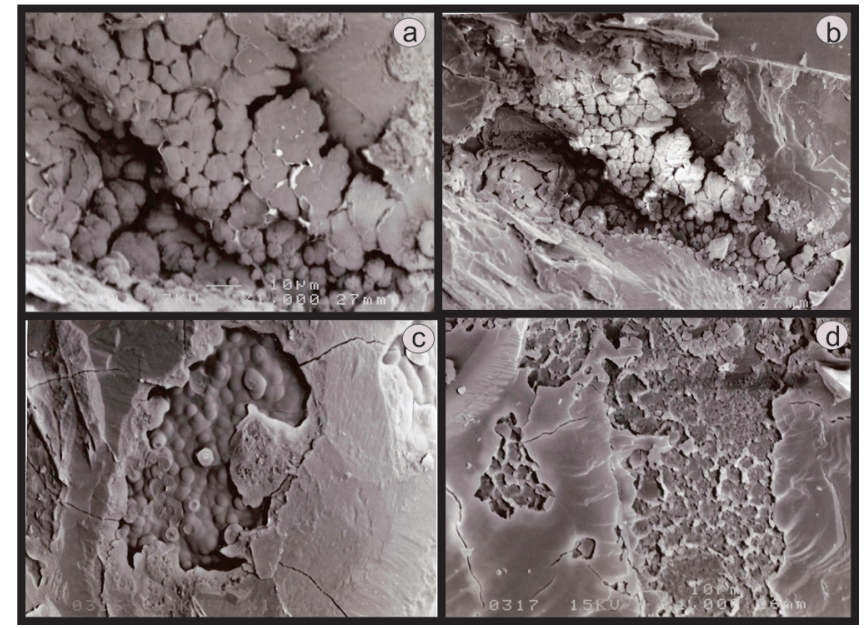

Figura 7. Micrografias SEM do foliose líquen Parmelia saxatilis ( $A$ e B) foram encontradas na superfície de parapeitos de pedra na Fortaleza de Santa Cruz; quando removidas, é possível observar danos causados por sua penetração na pedra (C e D).

Os microrganismos podem causar deterioração da pedra de várias maneiras: produção de ácido, penetração física, mobilização de cátions etc. (Allsopp et al., 2004). A descoloração da superfície pode ser causada por pigmentos dentro de microrganismos ou libertados por estes. Os fungos detectados nos edifícios são frequentemente de cor escura devido à melanina dentro das suas células e géneros com esta característica foram detectados em todos os edifícios amostrados nesta pesquisa. Os organismos fotossintéticos, algas e cianobactérias podem ser verdes, castanhos, rosados ou alaranjados, dependendo da sua produção de carotenos e pigmentos fotossintéticos e protetores. No entanto, o método NGS utilizado nestas amostras indicou a presença de poucas algas e os gêneros de cianobactérias identificados não eram aqueles conhecidos pela produção de pigmentos escuros. Um género de algas frequentemente encontrado em pedra e superfícies pintadas, a filamentosa trentepohlia tipicamente confere uma coloração vermelho alaranjada na superfície, causada por óleo contendo caroteno que pode manchar os cristais de pedra (Scheerer et al., 2009). Esta alga tem sido vista colonizando os parapeitos de pedra da Fortaleza de Santa Cruz, em Niterói (Ogawa et al., 2017b). No estudo atual, vários gêneros de bactérias e leveduras de cor rosa foram detectados nas igrejas de pedra pela NGS, incluindo Rubrobacter e Rhodotorula. Este último género de leveduras foi demonstrado como responsável por uma mancha rosa nas paredes internas da catedral de Évora, Portugal (Rosado et al., 2014). No entanto, mesmo no caso de microrganismos não pigmentados, estes produzem frequentemente materiais poliméricos fora das células que podem prender a sujidade e moléculas orgânicas, promovendo assim o aspecto sujo do edifício. A formação de tais biofilmes é certamente um fator que contribui para a deterioração e degradação das pedras. 


\section{CONCLUSÕES}

Os danos de edifícios históricos em pedra, monumentos e lugares arquitetônicos no Rio de Janeiro estão aparentemente acelerando. As estruturas estão sofrendo um rápido recuo de blocos, mostrando sintomas de grave decadência de pedras, que tem aumentado nas últimas décadas. As pedras utilizadas nos edifícios examinados neste relatório, Augen gnaisse e rocha granítica, são consideradas muito resistentes. No entanto, foi verificado que a maioria das fachadas históricas das igrejas apresentava graves degradações, principalmente manchas de ferro, desintegração granular, bolhas, fraturas incipientes e escamação de contornos. $O$ trabalho de campo e as análises petrográficas, SEM, químicas e biológicas identificaram componentes potenciais de importância para a compreensão dos processos que afetam a degradação das fachadas de pedra nas igrejas históricas da cidade do Rio de Janeiro. Os resultados do estudo geoquímico (cromatografia iônica e absorção atômica) demonstraram altas concentrações de vários elementos químicos que comprovam a importância dos sais nos processos de intemperismo; os elementos que apresentaram as maiores concentrações foram: SO4, NO3, Cl, Ca, K e Na. As correlações entre estes elementos demonstraram a ocorrência de vários sais; no entanto, os principais sais presentes em todos os edifícios foram halita $(\mathrm{NaCl})$ e gipsita $\left(\mathrm{CaSO}_{4} \cdot 2 \mathrm{H}_{2} \mathrm{O}\right)$. A ocorrência destes dois sais foi confirmada por análises SEM e petrográficas. Estes dois sais já foram demonstrados como agentes combinados muito eficazes para o envelhecimento do sal na cantaria. Este tipo de processo de envelhecimento "antropogênico" age concomitantemente com os processos naturais, acelerando a degradação que de outra forma ocorreria durante um período mais longo. Não só os sais, mas a colonização biológica das fachadas contribuiu para a decomposição física e química. As análises comprovaram a ocorrência dos seguintes organismos: fungos filamentosos, grupos de células bacterianas, diatomáceas raras e, especialmente as interessantes bactérias filamentosas fotossintéticas (cianobactérias), impregnadas com gesso recém-formado.

\section{AGRADECIMENTOS}

O financiamento para este projeto foi fornecido por meio da Coordenação de Aperfeiçoamento de Pessoal de Nível Superior (CAPES), uma bolsa de pesquisa da Fundação Carlos Chagas Filho de Amparo à Pesquisa do Estado do Rio de Janeiro (FAPERJ), e uma bolsa de pesquisa do Conselho Nacional de Desenvolvimento Científico e Tecnológico (CNPq). J.A. Baptista Neto é Pesquisador do Conselho Nacional de Desenvolvimento Científico e Tecnológico (CNPq).

Este artigo é dedicado em memória do professor Bernard J. Smith (Queen's University of Belfast).

\section{REFERÊNCIAS}

Allsopp, D., Seal, J., Gaylarde, C. 2004. Introduction to Biodeterioration. Cambridge: Cambridge University Press.

Amoroso, G.G., Fassina, V. 1983. Stone Decay and Conservation. Atmospheric Pollution, Cleaning, Consolidation and Protection. Materials Science Monographs 11, Elsevier, Amsterdam.

Azevedo, D.A., Moreira, L.S., Siqueira, D.S. 1999. Composition of extractable organic matter in aerosols from urban areas of Rio de Janeiro city, Brazil, Atmospheric Environment 33, 49875001. https://doi.org/10.1016/S1352-2310(99)00270-8

Baptista Neto, J.A., Smith, B.J., Mcalister, J.J., Silva, M.A.M Castanheira, F. 2006. Surface modification of a granite building stone in central Rio de Janeiro. Anais da Academia Brasileira de Ciências 78, 1-14. https://doi.org/10.1590/S000137652006000200011

Baptista Neto, J.A., Smith, B.J., Mcalister, J.J., Silva, M.A.M, Silva, A.L.C. 2011. Salt weathering of historical building stones in Rio de Janeiro central area: a case study of the São Francisco de Paula Church. In: Ioannou, I., Theodoridou, M. (Eds.). Salt Weathering on Buildings and Stone Sculptures, SWBSS, 19-22 oct. 2011, Limassol, Cyprus. p. 113-120. https://pdfs. semanticscholar.org/af32/0172cab4e5b1a33b16270acd3457 f8bc6769.pdf

Barrionuevo, M.R.E, Englert, G.E., Gaylarde, C.C. 2016. Physical and microbiological analysis of sandstone deterioration in the Argentine Jesuit missions. Geomicrobiology Journal 33, 671-676. https://doi.org/10.1080/01490451.2015.1079668

Bindschedler, S., Cailleau, G., Verrecchia, E. 2016. Role of fungi in the biomineralization of calcite. Minerals 6, 41. https://doi. org/10.3390/min6020041

Bonazza, A., Sabbioni, C., Ghedini, N. 2005. Quantitative data on carbon fractions in interpretation of black crusts and soiling on European built heritage. Atmospheric Environment 39, 2607-2618. https://doi.org/10.1016/j.atmosenv.2005.01.040

Brimblecombe, P., Grossi, C. M. 2007. Damage to buildings from future climate and pollution. APT Bulletin: The Journal of Preservation Technology 38, 13-18. https://www.jstor.org/ stable/40004714

Camuffo, D., Del Monte, M., Sabbioni, C. 1983. Origin and Growth mechanisms of the sulphated crusts on urban limestone. Water, Air, and Soil Pollution 19, 351-359. https://doi. org/10.1007/BF00159596

Canfora, L., Vendramin, E., Antisari, L.V., Papa, G.L., Dazzi, C., Benedetti, A., lavazzo, P., Adamo, P., Jungblut, A.D., Pinzari, F. 2016. Compartmentalization of gypsum and halite associated with cyanobacteria in saline soil crusts. FEMS Microbiology Ecology 92. https://doi.org/10.1093/femsec/fiw080 
Conti, M.E., Cecchetti, G. 2001. Biological monitoring: lichens as bioindicators of air pollution assessment - a review. Environmental Pollution 114, 471-492. https://doi.org/10.1016/ S0269-7491(00)00224-4

Crispim, C.A., Gaylarde, P.M, Gaylarde, C.C, Neilan, B.A. 2006. Deteriogenic cyanobacteria on historic buildings in Brazil detected by culture and molecular techniques. International Biodeterioration \& Biodegradation 57, 239-243. https://doi. org/10.1016/j.ibiod.2006.03.001

Daisey, J.M., Miguel, A.H, Andrade, J.B., Pereira, P.A.P., Tanner, R.L. 1987. An overview of the Rio de Janeiro aerosol characterization study. Journal of Air Pollution Control Association 37, 15-23. https://doi.org/10.1080/08940630.1987.10466194

De Los Ríos, A., Cámara, B., Del Cura, M.A.G., Rico, V.J., Galván, V., Ascaso, C. 2009. Deteriorating effects of lichen and microbial colonization of carbonate building rocks in the Romanesque churches of Segovia (Spain). The Science of the Total Environment 407, 1123-1134. https://doi.org/10.1016/j. scitotenv.2008.09.042

Del Monte, M., Sabbioni, C., Vitori, O. 1981. Airborne carbon particles and marble deterioration. Atmospheric Environment 15, 645-652. https://doi.org/10.1016/0004-6981(81)90269-9

Esbert, R.M., Díaz-Pache, F., Grossi, C.M., Alonso, F.J., Ordaz, J. 2001. Airborne particulate matter around the Cathedral of Burgos (Castilla y Leon. Spain). Atmospheric Environment 35,441-452. https://doi.org/10.1016/S1352-2310(00)001138

Fassina, V. 1991. Atmospheric pollutants responsible for stone decay. Wet and dry surface deposition of air pollutants on stone and the formation of black scabs. In: Zezza, F. (ed.). Weathering and Air pollution. Community of Mediterranean Universities, Bari, 67-86.

Fitzner, B., Heinrichs, K., Kownatzki, R. 1995. Weathering forms - classification and mapping/VerwitterungsformnKlassifizierung und Kartierung. Denkmalpflege und Naturwissenschaft, Naturstein-Konservierung, vol. 1. Berlin: Verlag Ernst \& Sohn. P. 41-88.

Gadd, G. M. 2017. The Geomycology of Elemental Cycling and Transformations in the Environment. Microbiology Spectrum 5, 1-16.

Galletti, G.C., Bocchini, P., Cam, D., Chiavari, G., Mazzeo, R. 1997. Chemical characterization of the black crust present on the stone central portal of St. Denis abbey. Journal of Analytical Chemistry 357, 1211-1214.

Gaylarde, C., Baptista, Neto, J.A., Ogawa, A., Kowalski, M., Celikkol-Aydin, S., Beech, I. 2017a. Epilithic and endolithic microorganisms and deterioration on stone church facades subject to urban pollution in a sub-tropical climate, Biofouling 33, 113-127. https://doi.org/10.1080/08927014.2016.1269893
Gaylarde, C., Ogawa, A., Beech, I., Kowalski, M., Baptista Neto, J.A. 2017b. Analysis of dark crusts on the church of Nossa Senhora do Carmo in Rio de Janeiro, Brazil, using chemical, microscope and metabarcoding microbial identification techniques. International Biodeterioration \& Biodegradation 117: 60-67.

Gaylarde, C.C., Gaylarde, P.M., Neilan, B.A. 2012. Endolithic phototrophs in built and natural stone. Current Microbiology 65,183-188. https://doi.org/10.1007/s00284-012-0123-6

Gaylarde, C.C., Ortega-Morales, B.O., Bartolo-Perez, P. 2007. Biogenic black crusts on buildings in unpolluted environments. Current Microbiology 54, 162-166. https://doi.org/10.1007/ s00284-006-0432-8

Gerbersdorf, S.U., Wieprecht, S. 2015. Biostabilization of cohesive sediments: revisiting the role of abiotic conditions, physiology and diversity of microbes, polymeric secretion, and biofilm architecture. Geobiology 13:68-97. https://doi. org/10.1111/gbi.12115

Goudie, A., Viles, H. 1997. Salt weathering hazards. London, UK: John Wiley \& Sons.

Iñigo, A.C., Vicente-Tavera, S. 2001. Different degrees of stone decay on the inner and outer walls of a Cloister. Building and Environment 36, 911-917. https://doi.org/10.1016/S0360$-1323(00) 00055-X$

Instituto Brasileiro de Geografia e Estatística - IBGE. 2014. Estatísticas populacionais, sociais, políticas e culturais. http:// www.ibge.gov.br/seculoxx/default.shtm (accessed 09.08.17).

International Council on Monuments and Sites - ICOMOS. 2008. Illustrated Glossary on Stone Deterioration Patterns. Monuments and Sites XV. https://www.icomos.org/publications/monuments_and_sites/15/pdf/Monuments_and_Sites_15_ISCS_Glossary_Stone.pdf

Jordan, M.M., Sanfeliu, T., Gómez, E.T., Pallarés, S., Vicente, A.B. 2009. A valuation of the influence of particulate atmospheric aerosol in constructions of the cultural and architecture patrimony of the urban area of Castellon (NE, Spain). Water, Air, and Soil Pollution 200, 245-251. https://doi.org/10.1007/ s11270-008-9908-4

Mansur, K.L., Carvalho, I.S., Delphin, C.F.M., Barroso, E.V. 2008. O Gnaisse Facoidal: a mais Carioca das Rochas. Anuário do Instituto de Geociências 31, 9-22.

McAlister, J.J. 1996. Analytical Techniques for the Examination of Building Stone. In: Smith, B.J., Warke, P.A. Processes of Urban Stone Decay. London: Routledge, p. 171-193.

Meldrum, F., Cölfen, H. 2008. Controlling mineral morphologies and structures in biological and synthetic systems. Chemical Reviews 108, 4332-4432. https://doi.org/10.1021/ cr8002856 
Moreira-Nordemann, L.M, Forti, M.C, Dilascio, V,L, Monteiro do Espírito Santo, C., Danelon, O.M. 1988. Acidification in Southeastern Brazil. In: Rodhe, H., Herrera, R. (Eds). Acidification in Tropical Countries, Scope 36, Chichester: Willey. p. 257-296.

Moropoulou, A., Bisbikou, K., Van Grieken, R., Torfs, K., Polikreti, K. 2001. Correlation between aerosols, deposits and weathering crusts on ancient marbles. Environmental Technology 22, 607-618.

Mottershead, D., Gorbushina, A., Lucas, G., Wright, J. 2003. The influence of marine salt, aspect and microbes in the weathering of sandstone in two historic structures. Building and Environment 38, 1193-1204. https://doi.org/10.1016/S03601323(03)00071-4

Ogawa, A., Celikkol-Aydin, S., Gaylarde, C., Baptista-Neto, J.A., Beech, I. 2017a. Microbiomes of biofilms on decorative siliceous stone: Drawbacks and advantages of Next Generation Sequencing. Current Microbiology 74, 848-853. https://doi. org/10.1007/s00284-017-1257-3

Ogawa, A., Celikkol-Aydin, S., Gaylarde, C., Baptista-Neto, J.A., Beech, I. 2017b. Microbial communities on painted wet and dry external surfaces of a historic fortress in Niterói, Brazil. International Biodeterioration \& Biodegradation 123, 164-173. https://doi.org/10.1016/j.ibiod.2017.06.018

Ortega-Calvo, J. J., Hernandez-Marine, M., Saiz-Jimenez, C. 1991. Biodeterioration of building materials by cyanobacteria and algae. International Biodeterioration 28, 165-185. https://doi.org/10.1016/0265-3036(91)90041-O

Piervittori, R., Salvadori, O., Isocrono, D. 2004. Literature on lichens and biodeterioration of stonework. IV. Lichenolologist 36: 145-157. https://doi.org/10.1017/S0024282904014136

Pozo-Antonio, J.S., Rivas, T., López. A.J., Fiorucci, M.P., Ramil, A. 2016. Effectiveness of granite cleaning procedures in cultural heritage: A review. Science of the Total Environment 571, 1017-1028. https://doi.org/10.1016/j.scitotenv.2016.07.090

Quiterio, S.L., Sousa da Silva, C.R., Arbilla, G., Escaleira, V. 2004. Metals in airborne particulate matter in the industrial district of Santa Cruz, Rio de Janeiro, in an annual period. Atmospheric Environment 38, 321-331. https://doi.org/10.1016/j.atmosenv.2003.09.017

Ricardo, A., Mansur, K.L., Barroso, E., Senra, F., Avellar, G., Ribeiro, R.C. 2017. Mapeamento das morfologias de alteração das rochas do Paço Imperial, Rio de Janeiro. Geologia USP. Série Científica, 17, 45-58. https://doi.org/10.11606/issn.23169095.v17-305

Rodriguez-Navarro, C., Sebastian, E. 1996. Role of particulate matter from vehicle exhaust on porous building stones (limestone) sulfation. Science of the Total Environment 187, 79-91. https://doi.org/10.1016/0048-9697(96)05124-8

Rosado, T., Reis, A., Mirão, J., Candeias, A., Vandenabeele, P., Caldeira, A.T. 2014. Pink! Why not? On the unusual colour of Évora Cathedral. International Biodeterioration \& Biodegradation 94, 121-127. https://doi.org/10.1016/j. ibiod.2014.07.010

Sabbioni, C. 1995. Contribution of atmospheric deposition to the formation of damage layers. Science of the Total Environment 167, 49-55. https://doi.org/10.1016/0048-9697(95)04568-L

Sabbioni, C., Zappia, G. 1992. Decay of sandstone in urban areas correlated with atmospheric aerosol. Water, Air, and Soi Pollution 63, 305-316. https://doi.org/10.1007/BF00475497

Sabbioni, C., Zappia, G., Gobbi, G. 1996. Carbonaceous particles and stone damage in a laboratory exposure system. Journal of Geophysical Research: Atmospheres 101, 19621-19627. https://doi.org/10.1029/95JD03755

Saiz-Jimenez, C. 1991. Characterization of organic compounds in weathered stones. In: Baer, N.S., Sabbioni, C., Sors, A.I. Science, Technology and European Cultural Heritage. Oxford: Butterworth-Heinemann. p. 523-526.

Sanjurjo Sánchez, J., Alves, C.A.S., Vidal Romaní, J.R., Fernández Mosquera, D. 2009. Origin of gypsum-rich coatings on historic buildings. Water, Air, and Soil Pollution 204, 53-68.

Scheerer, S., Ortega-Morales, O., Gaylarde, C. 2009. Chapter 5, Microbial deterioration of stone monuments-an updated overview. In: Laskin, A. I., Sariaslani, S., Gadd, G. M. (Eds.). Advances in Applied Microbiology, Vol. 66, Elsevier Inc. p. 97-139.

Silva, B., Aira, N., Martinez-Cortizas, A., Prieto, B. 2009. Chemical composition and origin of black patinas on granite. The Science of the Total Environment 408, 130-137. https://doi. org/10.1016/j.scitotenv.2009.09.020

Smith, B.J., Baptista Neto, J.A., Silva, M.A.M., Warke, P., Mcalister, J.J., Curran, J. M. 2004. Conservation of colonial built heritage: practical considerations and cultural constraints in Rio de Janeiro. Environmental Geology 46, 493-503.

Smith, B.J., Magee, R.W. 1990. Granite weathering in an urban environment: an example from Rio de Janeiro. Singapore Journal of the Tropical Geogtaphy II, 143-153. https://doi. org/10.1111/j.1467-9493.1990.tb00023.x

Smith, B.J., McAlister, J.J., Baptista Neto, J.A., Silva, M.A.M. 2007. Post-depositional modification of atmospheric dust on a granite building in central Rio de Janeiro: implications for surface induration and subsequent stone decay. In: Přikryl, R., Smith, B.J. (Eds.). Building stone decays: from diagnosis to conservation. Geological Society, London, Special Publication 271, 153-166.

Smith, B.J., Turkington, A.V., Warke, P.A., Basheer, P.A.M., Mcalister, J.J., Meneely, J., Curran, J.M. 2002. Modelling the rapid retreat of building sandstones. A case study from a polluted maritime environment. In: Siegesmund, S., Weiss, T., Vollbrecht, A. (Eds). Natural Stone, Weathering Phenomena, 
Conservation Strategies and Case Studies. Geological Society, London, Special Publications 205, 339-354. https://doi. org/10.1144/GSL.SP.2002.205.01.25

Sterflinger, K., Pinar, G. 2013. Microbial deterioration of cultural heritage and works of art - tilting at windmills. Applied Microbiology and Biotechnology 97, 9637-9646. https://doi. org/10.1007/s00253-013-5283-1

Tazaki, K., Asada, R., Lindenmayer, Z.G., Shirotori, T., Vargas, J.M., Nowatzki, C.H., Coelho, O.W. 2009. Life inhabits rocks: clues to rock erosion from electron microscopy of pisolite at a UNESCO heritage site in Brazil. International Journal of Earth Scinces 98, 227-238. https://doi.org/10.1007/s00531-0070270-3
Torok, A. 2003. Surface strength and mineralogy of weathering crusts on limestone buildings in Budapest, Building and Environment 38, 1185-1192. https://doi.org/10.1016/S03601323(03)00072-6

Van Grieken, R., Gysels, K., Hoornaert, S., Joos, P., Osan, J., Szaloki, I., Worobiec, A. 2000. Characterisation of individual aerosol particles for atmospheric and cultural heritage studies. Water, Air, and Soil Pollution 123, 215-228. https://doi. org/10.1023/A:1005215304729

Xu, F., Tang, J., Gao, S. 2010. Characterization and origin of weathering crusts on Kylin carved-stone, Kylin countryside, Nanjing-a case study. Journal of Cultural Heritage 11, 228232. https://doi.org/10.1016/j.culher.2009.11.006

Recebido: 19 fev. 2020

Aprovado: 19 fev. 2020

DOI: 10.20985/1980-5160.2020.v15n1.1621

Como citar: Baptista Neto, J.A., Gaylarde, C., Beech, I. et al. (2020), Degradação de gnaisse e granito em fachadas de edifícios históricos no centro do Rio de Janeiro, Revista S\&G 15, No. 1, 80-90. https://revistasg.emnuvens.com. br/sg/article/view/1621 